BENM 2021

International Scientific and Practical Conference "Biotechnology, Ecology, Nature Management"

\title{
IMPROVEMENT OF THE TECHNOLOGY OF SEPARATION OF UTFEL I CRYSTALLIZATION IN BATCH CENTRIFUGES
}

\author{
Anatoliy A. Slavyansky (a), Natalia V. Nikolaeva (b)*, Vera A. Gribkova (c), \\ Natalia N. Lebedeva (d), Daria P. Mitroshina (e) \\ *Corresponding author
}

(a) K.G. Razumovsky Moscow State University of Technologies and Management (the First Cossack University),

Moscow, Russia, slavyanskiyaa@mgutm.ru

(b) K.G. Razumovsky Moscow State University of Technologies and Management (the First Cossack University), Moscow, Russia,n.nikolaeva@mgutm.ru

(c) K.G. Razumovsky Moscow State University of Technologies and Management (the First Cossack University), Moscow, Russia, vera_gribkova@list.ru

(d) K.G. Razumovsky Moscow State University of Technologies and Management (the First Cossack University), Moscow, Russia, na.lebedeva@mgutm.ru

(e) K.G. Razumovsky Moscow State University of Technologies and Management (the First Cossack University), Moscow, Russia, d.mitroshina@mgutm.ru

\begin{abstract}
The yield and quality indicators of crystalline white sugar are largely determined by the technological conditions of the process of centrifugation of utfel I crystallization. The centrifugation process is a rather complex, step-by-step process, which is influenced by a large number of different factors, such as, for example, the technological properties of the centrifuged system, the kinetic and geometric parameters of the centrifuge, etc. Therefore, the improvement of the technology of boiling and, accordingly, centrifugation of the obtained wafers After crystallization together has a positive effect on the yield and quality indicators of commercial sugar. The authors of this article present an improved method for centrifuging utfel I crystallization based on mother utfel, which is confirmed by comparing the results of practical studies obtained during the centrifugation process according to the proposed and standard methods. The results presented in the article show an increase in the yield of crystalline white sugar during its boiling and centrifugation, while improving its quality.
\end{abstract}

2672-8575 (C) 2022 Published by European Publisher.

Keywords: Batch centrifuges, Boiling of utfel, Centrifugation of I utfel, Improved method of centrifugation of I utfel, Mother utfel 


\section{Introduction}

The so-called transition period is of particular importance for the correct understanding of the laws of the centrifugation process. This period in the scheme of operation of batch centrifuges begins at the moment when the separation rate of the intergranular solution of utfel becomes greater than the deformation rate of crystals, that is, after their compaction is completed. It is during this period that the saturation level of the liquid phase moves to the filter surface of the centrifuge rotor wall. The completion of this period of centrifugation for utfel I crystallization coincides with the beginning of washing of sugar crystals (removal of the intercrystal solution film from their surface).

The knowledge of the regularities of utfel centrifugation during the transition period is of not only scientific, but also practical interest, for example, to clarify the separation time of the intercrystal solution.

The basic equation of the transition period of centrifugation has the following form

$$
\frac{V \cdot \mu}{2 \pi \cdot K \cdot l} \cdot \ln \frac{R_{0}}{R}=\frac{\rho \cdot \omega^{2}}{2}\left(R_{0}^{2}-R^{2}\right)+\frac{\rho}{2}\left(U_{1}^{2}-U_{2}^{2}\right)
$$

$\mathrm{V}$ is the amount of intercrystal solution passing through the filtering partition per unit time; $\mathrm{K}$ is the permeability coefficient of the sugar crystal layer; L is the height of the sugar crystal layer, usually equal to the height of the rotor; $\mathrm{R}$ is the radius of this coaxial surface of the intercrystal solution; $\mathrm{R} 0$ is the inner radius of the filtered partition; $\mu$ is the viscosity of the intercrystal solution; $p$ is the density of the intercrystal solution; $\omega$ is the angular velocity of the rotor; $U_{1}^{2}$ и $U_{2}^{2}$ are the filtration flow velocity at radii, respectively R1 and R0.

\section{Problem Statement}

The conducted research in this area allowed us to conclude that the filtration rate of the intercrystal solution during this period has a constant value depending on the technological properties of the wafer, kinetic and geometric parameters of centrifuges.

It should be noted that the centrifuges used in sugar production are also not without some disadvantages, for example, due to air circulation through a layer of sugar crystals or the lack of control over the separation of outflows. In addition, often in the known methods of production of crystalline white sugar, which provide for the separation of the crystallization layer I in filter centrifuges, there are no clear requirements for the production of crystallization centers, the conditions for their build-up, which can cause heterogeneity of sugar crystals, and the conditions for washing sugar crystals are not clearly specified, which together can lead to significant deterioration in the quality indicators of commercial white sugar (Semenov et al., 2017, 2018a, 2018b, 2019).

\section{Purpose of the Study}

The inter-crystal solution of utfel in periodic centrifuges is separated from the crystals in accordance with the known theories of centrifugal filtration in two stages. On the first of them, centrifugal filtration takes place with an increasing layer of sugar crystals. The crystals are arranged according to the principle of the maximum possible packing, as in ordinary filtration, under the influence of an intercrystal solution moving in the pores (Figure 1). 


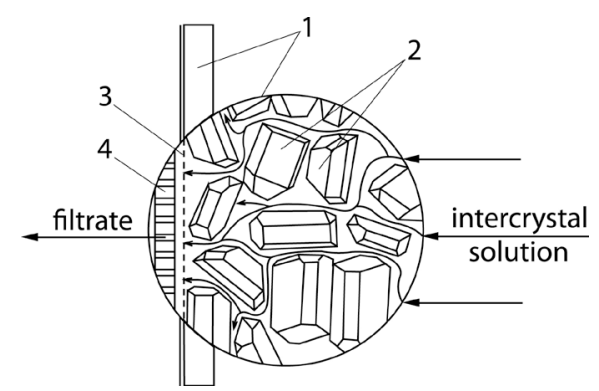

Figure 1. Flow diagram of the intercrystal solution in the centrifuge rotor: 1-a layer of sugar crystals, 2sugar crystals, 3-a sieve, 4-a perforated surface

The duration of the first stage practically coincides with the loading period, that is, it is only a small part of the total time of centrifugation.

During the second stage, the pore space is released from the intercrystal solution. This process is rapidly decaying - the film content on sugar crystals is inversely proportional to the square of the duration of centrifugation.

The conducted studies on its quantitative modeling have shown that the duration of both the first and second periods of centrifugation slightly differ in time and depends on the size of sugar crystals (Slavyansky, 2006).

At the end of the second period, the centrifuged mass quickly turns into a three - phase system-a skeleton of sugar crystals with a film of intercrystal solution on their surface and pores penetrating the sugar sediment layer along its entire height. Therefore, during this period, the separation of the intercrystal solution occurs not only under the influence of centrifugal force, but also due to the blowing of its film from the surface of the crystals by air passing through their pore space. At the same time, the air, being unsaturated with moisture, simultaneously dries the film of the intercrystal solution on the surface of the crystals, increasing its viscosity and making it difficult to separate. The continuation of centrifugation, due to drying, leads to cementation of sugar in the rotor and to difficulties associated with its unloading from the centrifuge (Shtangeev, et al., 2004).

In order to solve this problem, a more efficient method of producing crystalline white sugar was developed.

\section{Research Methods}

In accordance with this method, a mother wafer with a crystal size of $0.120-0.160 \mathrm{~mm}$ is used as crystallization centers, which is heated at a content of $88.0-90.0 \%$ of dry substances in the wafer. Under these conditions, the maximum rate of crystal growth is ensured, which accelerates the process of boiling the waffle. Also, the use of royal jelly as a seed improves the quality indicators of sugar, for example, the uniformity of crystals and a decrease in the number of fused crystals in the total mass of sugar. The increased amount of fused crystals in the total mass of sugar negatively affects not only the granulometric composition of sugar, but also its physico-chemical parameters. The presence of a large number of such crystals can lead to a deterioration of the conditions not only for boiling wafers, but also for their separation in the field of centrifugal forces, which in turn contributes to a decrease in sugar yield, an 
increase in the duration of technological operations of boiling and centrifugation and a decrease in the quality of crystalline white sugar.

After the amount of utfel in the vacuum apparatus is sufficient, a part of it, at the rate of $30-40 \%$ of the total mass, is taken in a mixture with syrup to the second apparatus as a crystal base. The selection of a part of the waffle as a crystal base increases the efficiency of the boiling process.

The remaining part of the wafer in the first vacuum apparatus is boiled to $92.0-92.5 \%$ of dry substances, and in the second apparatus it is condensed to $93.0-93.5 \%$ of dry substances, which is due to the difference in the time of their separation in centrifuges for 50-60 minutes. Boiling the waffle in the second vacuum apparatus to $93.0-93.5 \%$ of dry substances allows achieving a deeper depletion of the intercrystal solution and increasing the sugar yield (Daishev, 1993).

In Figures 2 and 3 show the dependences of changes in the content of dry substances and the color of the wafer I crystallization during its boiling.

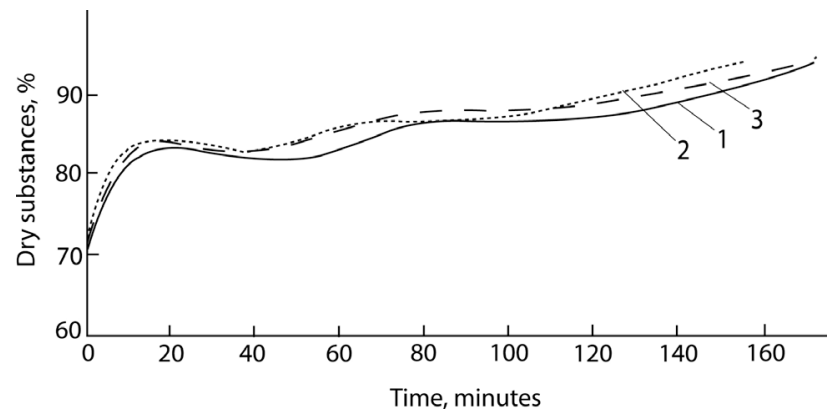

Figure 2. The nature of the change in the content of dry substances in the uthfel I crystallization during its boiling: $1-\mathrm{SV}$ sir $=54-58 \% ; 2-\mathrm{SV} \operatorname{sir}=58-65 \% ; 3-\mathrm{SV} \operatorname{sir}=65-70 \%$

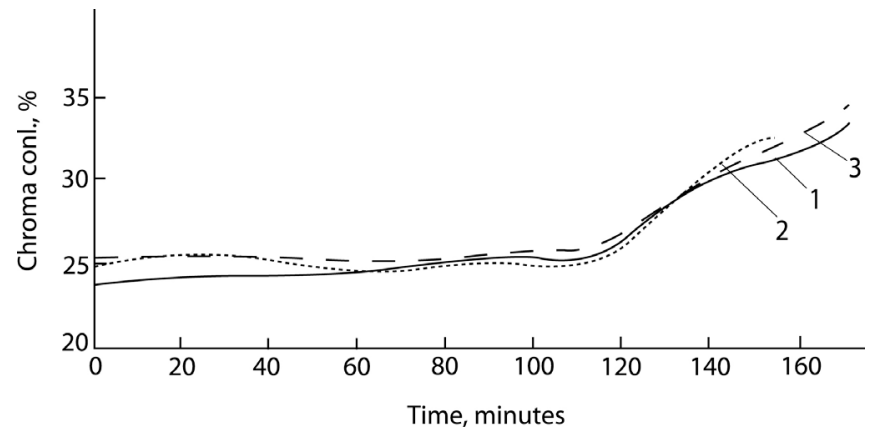

Figure 3. The nature of the change in the color of the wafer I crystallization during its boiling: 1-SVsir = $54-58 \% ; 2-$ SVsir $=58-65 \% ; 3-$ SVsir $=65-70 \%$

As can be seen from the figures, the best results are achieved when the duration of the waffle boiling process is on average 145 minutes with an increase in color by $8-10 \%$ (Tarasova, 2006).

Before the utfel is lowered from the second vacuum apparatus, it is swung by the first outflow of the utfel of their first vacuum apparatus to $92.0-92.5 \%$ of dry substances, which is due to its higher quality compared to the first outflow of the second vacuum apparatus (Slavyansky et al., 2015). 
After the utfel is lowered from the apparatus to the receiving utfel mixer, it is prepared for centrifugation. The general technological scheme of the food department according to the proposed method is shown in Figure 4.

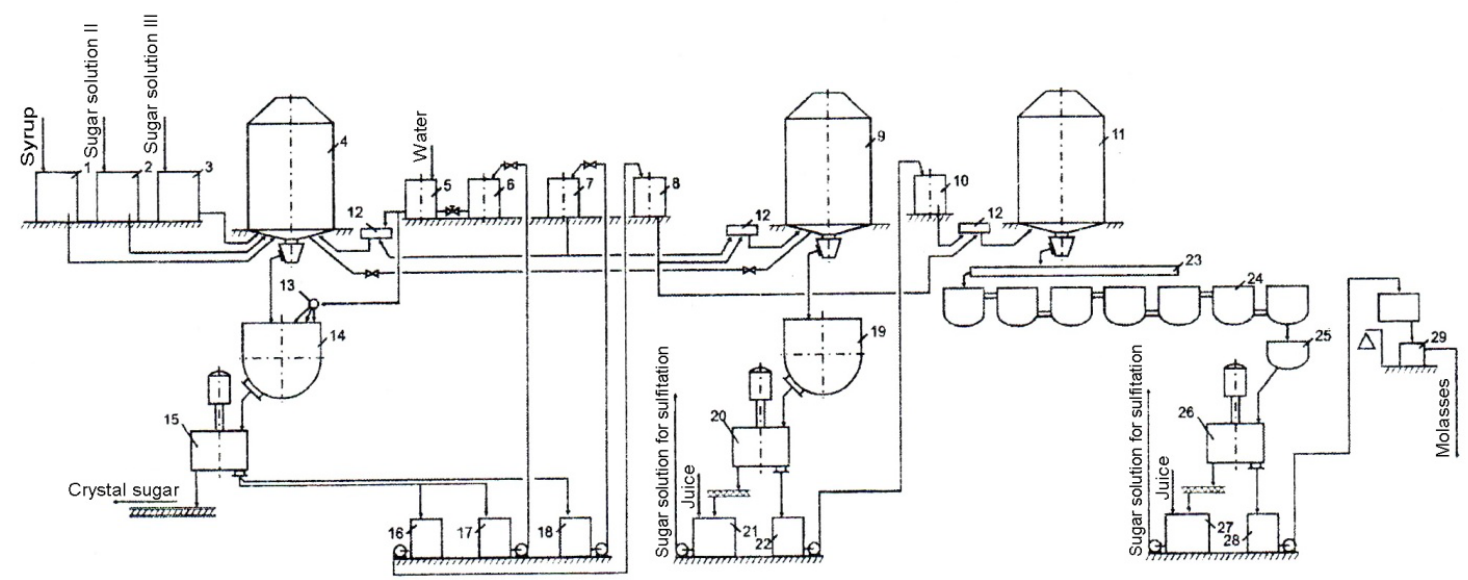

Figure 4. The scheme of the product department: 1 - a collection of syrup; 2 - a collection of sugar gluing II; 3 - a collection of sugar gluing III; 4 - a vacuum device I of the product; 5-a collection for preparing the first outflow for rocking utfel I; 6,17 - collections of the first outflow of the first stage of centrifugation of utfel I; 7, 18 - collections of the second outflow of utfel I; 8, 16 - collections of the first outflow of the second stage of centrifugation of utfel I; 9 - vacuum apparatus II of the product; 10, 22 - a collection of outflow of the utfel II; 11 vacuum device of the product III, 12 - collector; 13-perforated pipe for feeding the outflow to the utfel mixer; 14-utifelemeshalka-crystallizer; 15 - centrifuge I of the product; 19-receiving utifelemeshalka, 20 - centrifuge II of the product; 21-gluing apparatus; 23-receiving utifelemeshalka; 24-crystallization unit; 25-utifeleraspredelitel; 26-centrifuge III of the product; 27-gluing apparatus; 28-molasses collector; 29-scales

Moreover, the washing of sugar crystals is carried out in two stages - first with a sugar-containing solution with a concentration of $70-76 \%$ of dry substances in an amount of $2.5-3.5 \%$ by weight of the wafer at a temperature of 70-90\%, and then with steam at a pressure of 0.3-0.4 Mpa in an amount of 1.5$2.0 \%$ by weight of the wafer.

Utfel separation is carried out in automated periodic centrifuges FPN-1251T with a single loading of the centrifuge with utfel weighing $700 \mathrm{~kg}$ (Figure 5). 

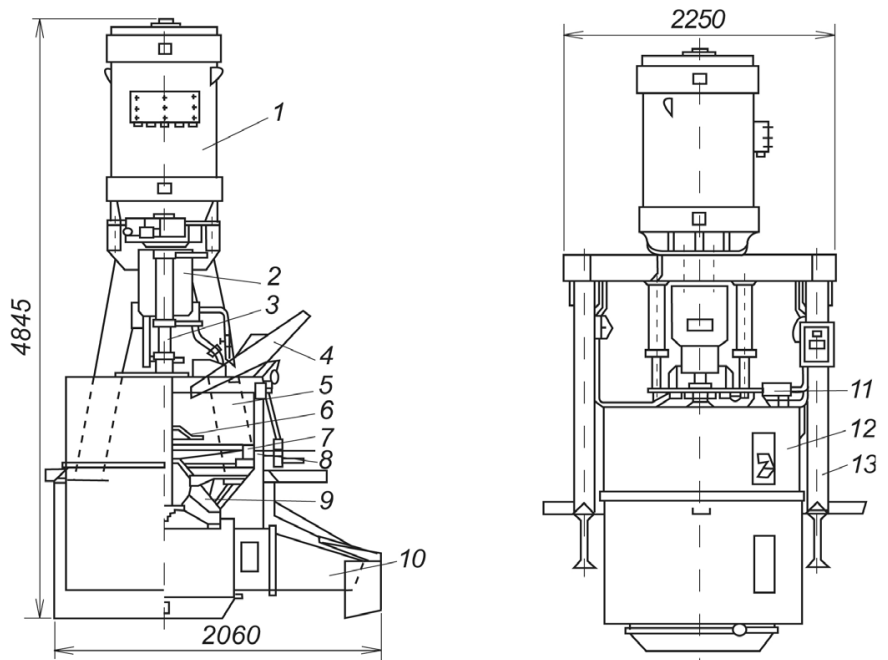

Figure 5. Centrifuge FPN-1251T-01: 1-electric motor; 2-suspension; 3-shaft; 4-tray; 5-rotor; 6-disk; 7 lifting pipe; 8-sugar unloading mechanism; 9-shut-off cone; 10-segregator; 11-loading regulator; 12-casing; 13-metal structure

The centrifuges used for the separation of utfel I crystallization are automatic batch filtering machines. The crystallization utfel I is separated in them without cooling immediately after it's unloading from the vacuum apparatuses to the receiving utfel mixer. The main components of any batch-acting filter centrifuge are a vertical perforated rotor 5 rotating on the shaft 3, placed in the casing 12, and its drive of the electric motor 1 . The direct separation of the wafer is carried out in the perforated cylindrical rotor of the centrifuge. When the rotor rotates rapidly, the wafer layer located on the screen surface is pressed against it by centrifugal force, the intercrystal solution is filtered through the sugar crystal sediment layer, passes through the holes of the lining sieves, enters the space formed by the rotor and the casing (the back-air space), flows into its lower part, from where it is discharged from the centrifuge. The layer of sugar crystals remaining on the sieve contains a part of the intercrystal solution in the form of a film, which is removed when it is washed with hot water. Auxiliary units of the centrifuge include devices for feeding wafer 4, washing and steaming sugar, separating outflows (segregator 10), braking the drive for unloading sugar 8 and 9, as w).

To separate the wafer from the first and second vacuum apparatuses, centrifuges equipped with separate collectors for the first and second outflows are used. Moreover, the centrifuges are equipped with a device that allows the washing of crystals to begin at the moment of separation of the bulk of the intercrystal solution, which reduces the consumption of washing water and increases the yield of crystalline sugar from the centrifuges (Figure 6). 

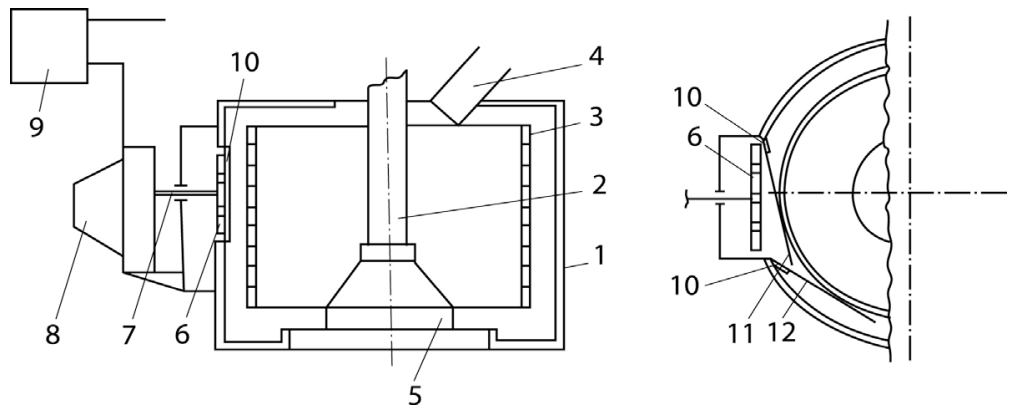

Figure 6. A centrifuge with a device that regulates the start of washing crystals: 1-the body, 2-the shaft, 3-the rotor, 4-the loading device, 5-the unloading device, 6-the perforated reflective shield, 7the rod, 8-the flow force meter, 9-the unit regulating the operation of the centrifuge, 10-plates,

11 and 12-tangents

The centrifuge works as follows. After loading the centrifuge with utfel, the separation of the first outflow begins. The edema drops coming out of the rotor during its rotation affect the reflective shield with a force proportional to the speed of centrifugal filtration. The force acting on the reflective shield is transmitted by the rod to the impact force meter of the detachable compartment, which converts the condition perceived by the reflective shield into a standard output signal, which is transmitted to the recording, regulating and actuating mechanism. This mechanism continuously measures the magnitude of the impact force of the separating compartment, which increases from a certain minimum value to a maximum and decreases to the same value as the first outflow is separated. At the end of the separation of the first outflow, the actuator turns on the washing of sugar. In this case, the second outflow is separated, which, like the first one, affects the reflective shield, and the transfer of forces occurs in the same way as when the first outflow is separated (Andreev et al., 1988; Slavyansky et al., 2018, 2019).

\section{Results}

The use of combined washing of sugar crystals first with a sugar-containing solution, and then with steam, allows to improve its quality with less water consumption (Figure 7).

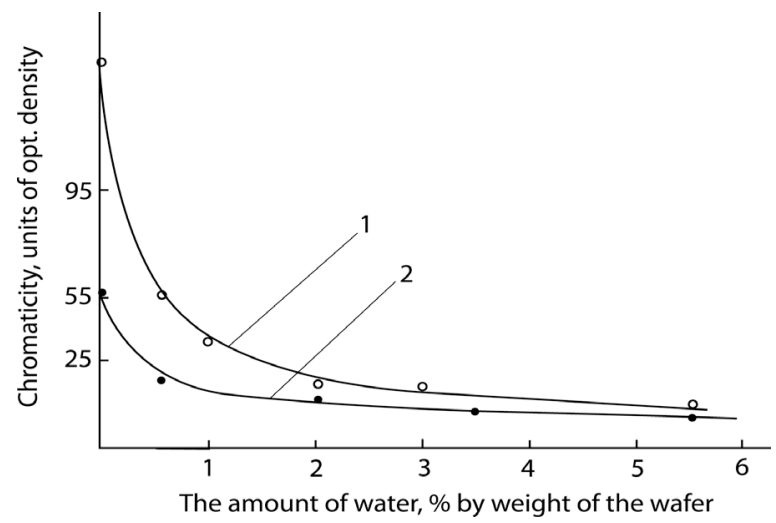

Figure 7. Change in the color of sugar when rinsed with water (1) and when rinsed with steam after washing with a sugar-containing solution (2) 
As can be seen from the figure, the use of a highly concentrated sugar-containing solution for washing sugar at the first stage (gluing, swelling) allows you to reduce the amount of water or steam consumed at the second stage by about 2 times.

Also, the use of a sugar-containing solution for washing crystals and the use of steaming instead of washing with water significantly reduces the dissolution of sugar crystals in centrifuges (Figure 8).

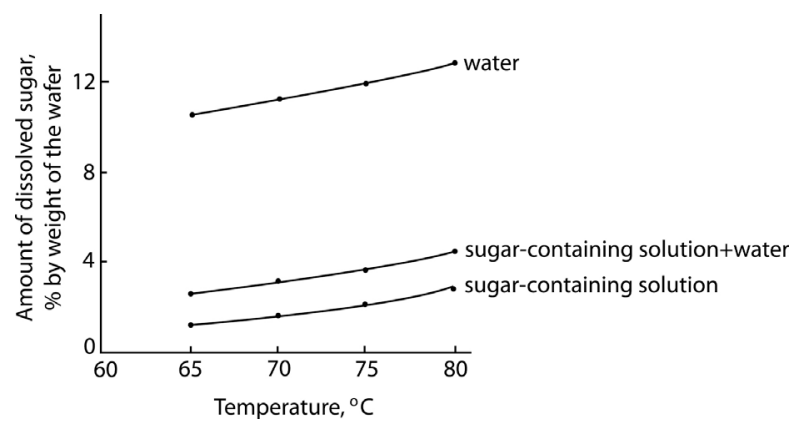

Figure 8. Dependence of the amount of dissolved sugar depending on the method of washing during centrifugation

As can be seen from Figure 8, during combined washing, the crystalline sugar is dissolved only by steam introduced for final washing. This method of washing sugar crystals allows not only to increase the yield of sugar, but also to improve its quality (Table 1).

Table 1. The main indicators of truffle and crystalline white sugar according to the known and proposed methods

\begin{tabular}{|c|c|c|c|}
\hline & \multirow[b]{2}{*}{ Indicators } & \multicolumn{2}{|c|}{ Methods of crystallization } \\
\hline & & $\begin{array}{l}\text { A well-known } \\
\text { method }\end{array}$ & $\begin{array}{c}\text { The proposed } \\
\text { method }\end{array}$ \\
\hline \multirow{5}{*}{$\begin{array}{l}\text { Technological } \\
\text { indicators of utfel }\end{array}$} & $\begin{array}{c}\text { The purity of the wafer of the first } \\
\text { crystallization in the first and vacuum } \\
\text { apparatuses, } \%\end{array}$ & 92,07 & 92,27 \\
\hline & $\begin{array}{l}\text { The content of dry substances in the wafers of } \\
\text { the first crystallization in the first vacuum } \\
\text { apparatuses, } \%\end{array}$ & 92,27 & 92,25 \\
\hline & $\begin{array}{l}\text { the purity of the wafer of the first } \\
\text { crystallization in the second vacuum } \\
\text { apparatuses, } \%\end{array}$ & 91,64 & 91,79 \\
\hline & $\begin{array}{l}\text { The content of dry substances in the wafers of } \\
\text { the first crystallization in the second vacuum } \\
\text { apparatuses, } \%\end{array}$ & 92,5 & 92,25 \\
\hline & $\begin{array}{l}\text { Average yield of sugar crystals from a } \\
\text { centrifuge for two wafers, } \%\end{array}$ & 50,8 & 50,8 \\
\hline \multirow{4}{*}{$\begin{array}{l}\text { Physico-chemical } \\
\text { parameters of } \\
\text { crystalline white } \\
\text { sugar }\end{array}$} & Chroma, units of opt. pl & 0,80 & 0,75 \\
\hline & Turbidity, physical units & 27,8 & 24,8 \\
\hline & The content of reducing substances, $\%$ & 0,042 & 0,038 \\
\hline & Mineral content, $\%$ & 0,037 & 0,026 \\
\hline $\begin{array}{l}\text { Granulometric } \\
\text { composition of }\end{array}$ & Average crystal size, $\mathrm{mm}$ & 69 & 81 \\
\hline $\begin{array}{l}\text { crystalline white } \\
\text { sugar }\end{array}$ & Coefficient of heterogeneity, $\%$ & 29,2 & 26,8 \\
\hline
\end{tabular}


Further research in this direction has shown that an indispensable condition for the operation of centrifuges, regardless of the quality of the separated wafer and its temperature, is to maintain the air environment in a state of moisture saturation. This is most efficiently achieved by introducing steam with a temperature of $130-140^{\circ} \mathrm{C}$ into the space inside the centrifuge rotor in the amount necessary to increase the temperature in this volume to the utfel temperature during the entire time of active centrifugation. However, the temperature difference between the wafer and the steam should not exceed $10^{\circ} \mathrm{C}$. With a larger difference, the sugar flushing into the outflow becomes noticeable (Figure 9) (Rogé et al., 2005).

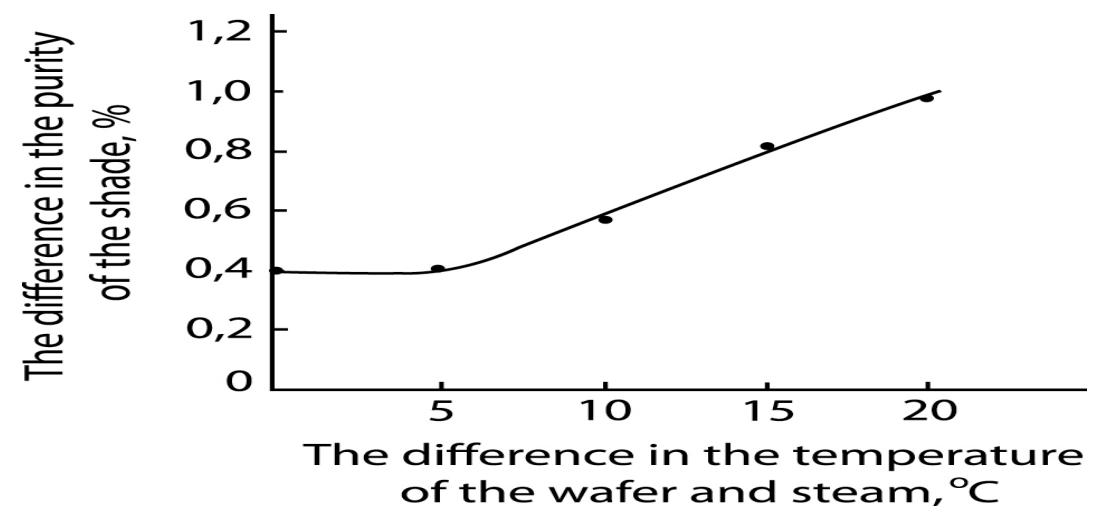

Figure 9. Enrichment of edema with sugar depending on the temperature difference between the waffle and steam

The degree of waterlogging of the air under these conditions can be very small - no more than $5 \%$ of the moisture content in the saturated air. And this fully guarantees the protection of the centrifugation process from undesirable phenomena associated with drying the centrifuged mass.

\section{Conclusion}

Thus, it can be seen from the materials presented in the article that the method proposed by the authors for obtaining crystalline white sugar in comparison with the traditional one allows increasing the sugar yield after boiling and centrifugation by $2.6 \%$ by weight of the wafer. In addition, the resulting crystalline white sugar also has slightly better quality indicators.

\section{References}

Andreev, V. G., Slavyansky, A. A., Sapronov, A. R., Trushkina, M. A., Strelnikov, V. I., \& Battalov, H. H. (1988). Filter centrifuge Byul. Auth. Certificate SU 1437090 A 1.

Daishev, M. I. (1993). Air conditioning in the centrifuge drum. Sugar industry, 1, 6-7.

Rogé, B., Mathlouthi, M., Burzawa, E., \& Genotelle, J. (2005). Centrifugal control and the quality of white sugar: Results from G.T.S. still of topical interest. Zentrifugenarbeit und Weißzuckerqualität: Ergebnisse des Groupement Technique de Sucreries noch immer zeitgemäßZuckerindustrie 130, 1.

Semenov, E. V., Slavyansky, A. A., \& Lebedeva, N. N. (2017). Washing of crystalline white sugar in the centrifuge rotor. Storage and processing of agricultural raw materials, 3, 36-39. 
Semenov, E. V., Slavyanskii, A. A., \& Karamzin, A. V. (2018a). Calculation of the process of separation of a suspension in a hydrocyclone. Chemical and Petroleum Engineering, 53(9-10), 559-567. https://doi.org/10.1007/s10556-018-0381-7

Semenov, E. V., Slavyansky, A. A., Karamzin, V. A., \& Karamzin, A. V. (2019). Implementation of the process of centrifugal fractionation of fine particles. Chemical and oil and gas engineering, 2, 2225. https://doi.org/10.1007/s10556-019-00591-z

Semenov, E. V., \& Slavyanskii, A. A. (2018b). Calculation of the process of separation of insoluble fluid systems. Chemical and Petroleum Engineering, 54(7-8), 466-471. https://doi.org/10.1007/s10556018-0503-2

Shtangeev, V. O., Kober, V. T., Belostotsky, L. G., Shtangeeva, N. I., Lagoda, V. A., \& Shestakovsky, V. A. (2004). Modern technologies and equipment for sugar beet production. Part 2. Tsukor Ukraini.

Slavyansky, A. A. (2006). Technological equipment of sugar factories: classification, technical characteristics, calculations, layout. Textbook for students of higher educational institutions studying in the specialty 260203 "Technology of sugar products".

Slavyansky, A. A. (2020). Special technology of sugar production (Textbook). The second edition is corrected. Lan.

Slavyansky, A. A., Alekseev, A. A., Gribkova, V. A., Nikolaeva, N. V., \& Makarova, S. A. (2019). To calculate the control device for the process of washing granulated sugar in a periodic centrifuge according to a "flexible" program. Sugar, 10, 22-26.

Slavyansky, A. A., Sergeeva, E. A., \& Makarova, S. A. (2015). Method of production of crystalline white sugar. Patent of The Russian Federation 2544596.

Tarasova, E. A. (2006). Improving the technology of obtaining utfel I crystallization depending on the quality of raw materials. [Dissertation for the degree of candidate] Technical Sciences in spec. 